\title{
Vocational Welding Excellence - Integration by Adopting AWS Level I and II Entry and Intermediate Level Welder Curriculum Guidelines and Welding Educator Certification under the American Welding Society Established Programs
}

\author{
Steven Snyder ${ }^{1}$, Dina Septriana ${ }^{2}$ \\ ${ }^{1}$ PT. Asian Welding Specialist Facility Consultant to PT. AWS at SMKN 2 Bandung, Ciliwung \\ no 4. Cihapit, Bandung. Jawa Barat. 4011 Indonesia \\ 2 PT. Asian Welding Specialist Facility at SMKN 2 Bandung Jl. Ciliwung no 4. Cihapit, \\ Bandung. Jawa Barat. 4011 Indonesia
}

\begin{abstract}
Integration of vocational welding curriculum and increasing the skill levels of the welding instructors is essential for success in Indonesia. This paper reflects on the current-status and direction of welder training in Indonesia and establishment of the American Welding Society (AWS) Accredited Welder Testing Facility at the SMK Negeri 2 Bandung Vocational High School located in Bandung, West Java, Indonesia. It introduces the first AWS SENSE Pilot Program (Schools Excelling through National Skills Education) Entry Level and Intermediate Level I and II Welder program in Indonesia at for this facility. Most importantly however, students can actually graduate from high school, with a real globally recognized welding education certificate from the American Welding Society, endorsed by the USDOE, listed in the American Welding Society database of educated welders meeting those requirements. Lastly, it will outline why and how Indonesian Vocational Welding Instructors can and should be required to demonstrate their teaching expertise by preparing and achieving the AWS Certification for Welding Educators.
\end{abstract}

Keywords: Welding; Vocational; Education; AWS; SENSE; SMK; USDOE

\section{INTRODUCTION}

There is a continuous global need for certified skilled welders, welding and robotic welding technologists, certified welding inspectors, welding equipment sales and welding engineers. Welding is as much of a science as an acquired skill. In the United States of America (USA), there is a current and ongoing severe shortage of welders. Fabricators in the United States, Australia, UK and many other developed nations are now facing the most acute workforce crisis in living memory. 
The coming workforce crises in welding [1]. The average US welding operator is 57 years old and getting set to retire. The average age of welders in the UK and Australia has now eclipsed 55. When the US Republican presidential candidate Marco Rubio declared in 2015 that "we need more welders and less philosophers", he succinctly nailed the problem. Most industry experts in USA and the American Welding Society are projecting there a shortage of 300,000 welders by the year 2020, and that is expected to rise to as much as 400,000 by 2024 in USA according to the American Welding Society. When there is a shortage of something needed, then it comes at a higher premium. Basically, this means welding will remain a stable job market with rising wages because of future demands; there could not be a better time to pursue a welding career. The average yearly earnings for welders in the USA in 2016 were between US $\$ 39,000$ and US $\$ 65,000$ for most common welding positions. These earnings double, or even triple, when entering certain specialized welding fields such as pipe welding and underwater welding, or choosing to travel on the job and receive benefits, i.e. as travel pay and per diem, such as pipelines, nuclear and power plant- x-rayquality welders.

Australia is also an illustration of what happens when demand for welders exceeds supply. In areas of short supply and high skill, welders in the US can earn over US\$100,000, however now in Australia, it is well over US\$200,000, and more than US $\$ 300,000$ on Australia's remote gas projects. A recent survey by the Structural Steel and Welding Trades Workers in Australia indicated [2]:

- Most surveyed vacancies involved a mix of fabrication and welding duties.

- Recruitment was particularly difficult in 2016.

- About 43 per cent of vacancies were filled; the lowest proportion since 2011.

- There were 3.8 applicants per vacancy on average, of whom only 0.6 were suitable. Applicant numbers have fallen each year since 2013, from an average of 6.5 and 1.8 suitable per vacancy.

- One third of employers did not attract any applicants.

If developed countries such as the USA and Australia are struggling, what does this mean for the future of other countries like Indonesia that do not have well established, harmonized and integrated quality welder training programs or need to import qualified and certified welders? It means foreign skilled labor taking these jobs from local underqualified talent and sending that income back to their host country.

Even Philippine government is now considering the possibility of reducing the number of skilled workers being deployed abroad to address local shortages of skilled welders and other manpower. The UAE has a constant need of skilled welders and must frequently rely on foreign labor. Vietnam has sent over a thousand AWS ATF Certified Welders since 2010 to UAE and Saudi Arabia and continues.

Welders are among the top ten hardest skills to find globally. In the UK, the country has just updated (last update on February 25, 2016) their list of shortage occupations, which includes roles that are difficult to fill up with the existing workforce in the country and can therefore be taken up by foreigners looking to 
make a move. For the welding trades, new entrant: $£ 18,000$; experienced: $£ 20,100$ [Source: Annual Survey of Hours and Earnings 2013]

There is enormous need for infrastructure in Indonesia; this, along with strengthening the potential of the shipyard building and repair industry as the main force in Indonesia's Maritime Sector, the Indonesian government's program to actualize electricity supply for the several planned power plants, means one thing for sure: a major need for entry level, intermediate, and advanced level skilled and certified code welders for many years to come. Indonesia needs to produce 3.8 million skilled workers annually to meet its target of becoming the seventh largest economy by 2030 [9].

Ministry of Manpower and Transmigration (MoMT) with the Indonesian Government, appear now focused on budgets for funding towards mainly only private welder training entities and Government BLK's, (MoMT) who oversee the Technical and Vocational Education and Training (TVET) Centers, with seemingly less efforts in working closer with the Ministry of Education and Culture (MOE) at allocating more funds at the SMK level which is where it should start for best results.

Manpower Minister Hanif Dhakiri said in the Jakarta Post, November 30, 2016, that currently Indonesia was the 16th biggest economy with 57 million skilled workers. In 2030, Indonesia would need 113 million skilled workers. There is a shortage of 56 million skilled workers that must be filled in 14 years he said. Hanif added that the government, through several ministries, would intensify vocational training. The Manpower Ministry would also focus on vocational training centers (BLKs) in coordination with industries. Currently, over 650 companies are working with the BLKs to provide internships, Hanif said [9].

Indonesia however, must be aggressive in the pursuit of fully integrating and harmonization of welder training while improving the welding instructor qualifications for improved curriculum. Individuals must be continually trained for the increasing technology in welding production in shipyards, automotive, infrastructure, refinery and power plants, LNG and oil and gas related projects, while striving to improve the overall quality and minimize the welding repairs for projects. Welding repairs over four times more than original welding cost. The welder of the future must have multiple technical skills with clear understanding of the safety, welding processes, procedures, equipment, materials and weld quality

In many places where there is high unemployment, where educational institutions are not seen to be responding to private sector demand for skills, or where specific groups are excluded from the workforce, the term "skills gap" is used to describe the problem. Although this may be the case at times, the characterization is unfortunate because it over-simplifies the issue, as there are a wide variety of factors influencing employment. If it were merely a 'skills-gap', then simple training programs should be able to solve the problem by closing the gap, but this has not worked. This is especially true in Indonesia which has a diverse and dynamic economy, labor force, and geography. At any given time, there will always be several skills needed by industry, and a set of parties who are or should be acting to address those needs. Often, the real problem lies in the inability of the two or three sets of parties to work together effectively: 
employers who demand skills; Ministry of Education and Culture, Ministry of Manpower, and other service providers as well as policymakers and civil society groups, who must draw on their strengths and assets, and use those collectively within the labor market system and available experts in those fields, to maximize the contribution of a region's workforce that can match to its economic development [3].

Youth unemployment for those aged 15 to 24 is a serious problem in Indonesia, according to a study on skilled labor within five Southeast Asian countries released by JP Morgan and Singapore Management University (SMU). Indonesia lacks skilled workers due to a huge gap between academia and industry, as educational institutions often do not train students to meet the needs of employers, according to a study on skilled labor within five Southeast Asian countries released on 1 November by SMU and global financial services firm J.P. Morgan. Commenting on the findings of the study, SMU President Professor Arnoud De Meyer noted that Indonesia should leverage its young workforce as a competitive advantage, and prioritize education and skills training — ensuring that there are sufficient numbers of qualified teachers and greater involvement by industry players, who can offer industrial apprenticeships and practical training for the country to achieve sustainable growth [7].

The skill level for welding instructors all over Indonesia delivering welder training needs to be addressed unilaterally and expeditiously. This includes both SMK and BLK facilities. The welding educators need to not just understand how to deliver classroom module content and presentations, but also the hands-on welding process and skills in multiple welding processes, by demonstrating and coaching the students, relative to local industry needs and demands while meeting higher standards as outlined in AWS SENSE. This is essential to producing skilled Entry Level, Intermediate and Advanced Level welders.

\section{METHODS}

The AWS Schools Excelling through National Skills Standards (SENSE) is a comprehensive set of standards and guidelines for welding education programs since 1994. The SENSE program began in the 1990s, with a grant from the United States Department of Education \& Labor to standardize welder training in the U.S.A.

The fact was well recognized by the American welding and fabrication industry, there were welders who were lacking basic skills, or whose skills varied greatly in the level of abilities, depending on their geographical location and school or program attended, which employers were having to accept welders with less than desired minimum basic welding skills.

The AWS Education Committee developed the "Guidelines for Welder Training", i.e. established standards for the training of entry, intermediate and advanced level welders. The benefits of SENSE participating Schools include, but are not limited to the following:

- Competency-based standards with ability to manage all student progress on-line via AWS SENSE portal for teachers and students 
- Provides minimum requirements for a welding program in a modular format

- Provides teachers with instructional guidelines and the online AWS Educator Member forum with extensive information to assist them

- Access to Technical Resources on-line from AWS SENSE Library

- Sample Welding Procedures Specifications (WPS) for welding students

- Modularized knowledge theory examinations provided for each Module

- Practical Exams and instruction provided for teachers for Welder Testing

- Health and Safety Information and recommended training for Instructor

There are nine separate modules for Level I, with a choice of the implementation approach that allows working with local industry needs for curriculum delivery by the instructor for the training, including: eight separate examinations; SENSE welder certificate and wallet card and online registration upon completion; online school locator; an easy access to program resources, available for online download; and is SENSE Accreditation approval.

A certificate or diploma from an AWS SENSE program provides graduates with an important credential for employment and continuing education, which can include high schools and colleges for the Level II Intermediate and Level III Advanced Welder curriculum. Students, instructors and prospective employers can be assured that the training and testing students receive is based on national standards and guidelines that are USDOE recognized. The process outline for SENSE program is illustrated in Figure 1.

\section{Process Flowchart}

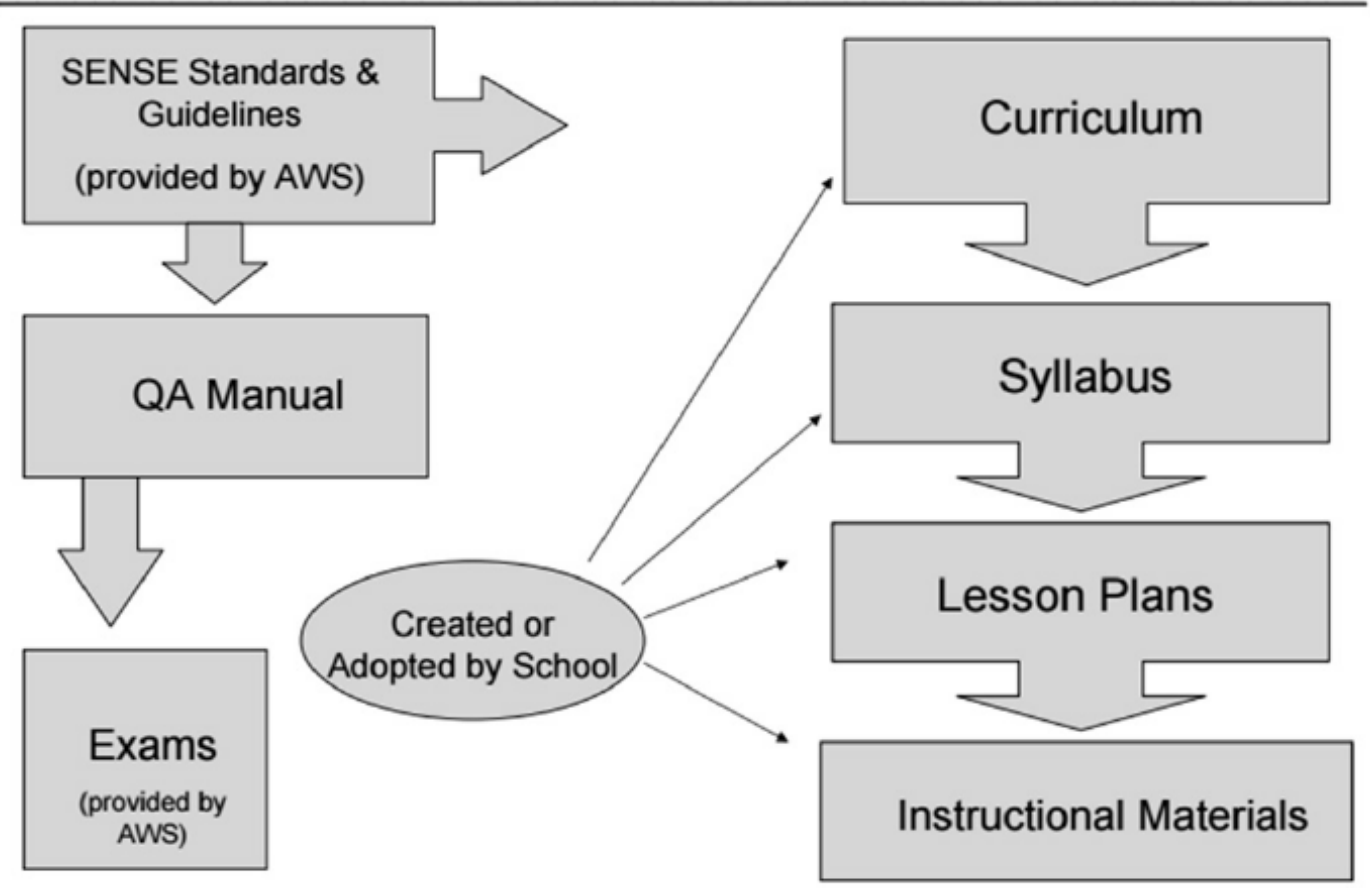

Figure 1. Process flowchart for a SENSE program 
A pilot program for AWS SENSE welders is underway at SMKN 2 Bandung since August 2017. Curriculum guideline outcomes for AWS SENSE Level I Entry Level program are shown in Figure 2. PT. Asian Welding Specialist (PT. AWS) has prepared and translated all AWS SENSE Level I curriculum, instructor lesson plans and theory examinations to Bahasa Indonesia for use at this facility only. Recommended student attendance is 600-900 hours for completion of nine modules for the Level I Entry Level Welder Program. Less than one third of that time is actual classroom based, and the instructors balance time between the classroom and the welding shop each week, with well over two-thirds of the time hands-on training, in- shop welding. The proper method to master welding skills is by doing it properly, with repeat, consistent and instructor lead practice.

PT. AWS, as an American Welding Society AWS Accredited Welder Testing Facility, AWS Educational Institution and AWS SENSE participating facility can assist the Ministry of Education and Culture at all SMK Vocational Welding programs by region in Indonesia, focusing on the local industrial sector needs, identifying and discussing the needs of local companies and industry and serve as a conduit to better align or modify the vocational welding curriculum for welding instructors to deliver trained and "ready to work" graduates from high school with AWS globally recognized welding education certificates.

To accomplish this, regional harmonization and integration must be implemented to support the regional labor force mobility.

Level I Outcomes

\begin{tabular}{|c|c|c|c|}
\hline Modules & \begin{tabular}{|c|} 
Passing \\
Score
\end{tabular} & Visual & Destructive \\
\hline 1 - Occupational Orientation * & No Test & No Test & No Test \\
\hline $2-$ Safety and Health of Welders * & $100 \%$ & No Test & No Test \\
\hline 3 - Drawing and Welding Symbol Interpretation * & $75 \%$ & No Test & No Test \\
\hline 4 - Shielded Metal Arc Welding & $75 \%$ & Pass /Fail & Pass /Fail \\
\hline 5-Gas Metal Arc Welding & $75 \%$ & Pass /Fail & No Test \\
\hline 6-Flux Cored Arc Welding & $75 \%$ & Pass /Fail & No Test \\
\hline 7 - Gas Tungsten Arc Welding & $75 \%$ & Pass /Fail & No Test \\
\hline $8-$ Thermal Cutting Process $* \dagger$ & $75 \%$ & No Test & No Test \\
\hline Unit 1 Manual Oxy fuel Gas Cutting (OFC) $\dagger$ & & Pass /Fail & No Test \\
\hline Unit 2 Mechanized Oxy fuel Gas Cutting $(\mathrm{OFC}) \dagger$ & & Optional & No Test \\
\hline Unit 3 Manual Plasma Arc Cutting $-\mathrm{PAC} \dagger$ & & Pass /Fail & No Test \\
\hline Unit 4 Manual Air Carbon Arc Cutting $\dagger$ & & Optional & No Test \\
\hline 9 - Welding Inspection and Testing * & $75 \%$ & Pass /Fail & No Test \\
\hline
\end{tabular}

Figure 2. https://app.aws.org/education/sense/completion 


\section{RESULTS}

Skills-based education is essential for any country to be competitive in a global market. This has been proven in history in a major way in Korea after WW II and many other east Asian countries since [5-6]. Indonesia can now take steps at the High School Vocational Education level, to integrate AWS approved welder training across all SMK facilities.

Implementation of the AWS SENSE program will directly impact the Indonesian economy by assisting to reduce the current high youth unemployment [7]. It can aid to resolve issues with underqualified or lack of skilled welders in Indonesia, as well as decrease dependency on the (MoMT) to invest primarily in BLK's and private welder training facilities as is currently being done. Those persons could have gained these skills and even better in high school, if they only had been afforded the opportunity instead of now at ages 1824 spending the funds.

Engaging local industries and soliciting feedback will allow SMK welding programs to meet the needs of the local businesses seeking skilled welding labor.

Likewise, the only way to assure that training is being conducted to meet the minimum skill requirements and assure comprehension, is to utilize properly trained, qualified and certified welding instructors.

The American Welding Society and US Department of Education endorsed program, meets and exceeds those currently used in Indonesia and would also aid to expedite additional trained welders entering the workforce with a globally recognized certificate in welding out of high school from the American Welding Society.

It is recognized after the authors review, the current written document for skills competition being used by LKS - SMK - NASIONAL requires expanded upon, as it is currently written to lower than the actual standards expected for the AWS Entry Level I Welder program and other High School Vocational Schools in USA, UK, Germany, Australia and many other East Asian countries. The document LKS-NAS-01, dated October 19, 2016, requires only very basic welding skill levels and abilities of the participating students in the competitions. The goal should be having integrated and harmonized welder training skills meeting AWS SENSE Level I and II to prepare and send more students representing Indonesia to the World Skills Competition for Welding, who have attended now in 2015 and 2017. The AWS SENSE programs will be a basis to allow this to be realized by other welding students as well achieve a medals or placement at those skills competitions.

Indonesian Vocational Welding Instructors can also become certified as AWS Certified Welders through an AWS Accredited Welder Testing Facility and display the ability to deliver the practical skills for curriculum, while working to achieve the AWS Certified Welding Educator credential as an instructor/teacher. Although there are optional programs now being offered in Indonesia for Certified Welders and Educators, i.e. German, Japanese and British, all affiliated with the Indonesia Welding Society (IWS) or other Certification Schemes for Welding Inspection Personnel, (CSWIP) it is key to note that these certification program options and welding societies were all 
created or formed long after the American Welding Society, founded in 1919. AWS developed and successfully launched these programs, on which all others are based in one or more parts after the well-established AWS Certification programs. The Certified Welding Educator (CWE) program requires and tests the instructor's ability to understand welding training requirements, prepare instruction plans, conduct training classes, and evaluate student performance.

The instructor shall:

- Use prepared instructional materials or develop their own original instructional materials;

- Be familiar with welding processes, welding procedures, welder qualifications, materials and the limitations of weld testing; and

- Can read drawings, prepare records, develop reports and maintain a valid welder certificate in at least one, however preferably three common arc welding processes.

A 2015 analysis on skills demands in Indonesia by USAID [3] was in response to a request from USAID/Indonesia to support the Mission to better understand the -drivers of skills needs in Indonesia.

It is a most relative and significant read for stakeholders engaged in vocational education training in Indonesia, which addresses many real obstacles that are still prevalent in Indonesia today, and provides a framework for understanding skills demand in Indonesia.

Despite increasing educational attainment across all levels and the Ministry of Education's push to increase vocational education, the quality of institutions remains a major concern, with many firms reporting that these graduates, despite going further in education, are still not well-prepared for the labor market.

Individuals, particularly those from poor and vulnerable populations, may also acquire work-readiness skills through non-formal education. These education and training programs are mainly provided by the Ministry of Education, the Ministry of Labor, non-governmental organizations, and the private sector. These programs are often a source of second chance education for disadvantaged groups; however, there is much variation in the quality of these programs with firms often unaware of these programs' existence and certifications/diploma's.

In 2014, The Ministry of Education increased compulsory education to twelve years of schooling. However, a report by UNESCO in 2015 [4], illustrated a wide range of different vocational training approaches being used.

The Author has over 25 years of vocational welding training experience in numerous countries and after reviewing numerous foreign aid studies relative to Indonesia Vocational Education and other East Asian countries, spending countless hours meeting with various Indonesian educators, welding companies and attending SMK facilities, it has been clearly ascertained that much work is still required to really harmonize and integrate quality vocational welding education and reduction of the several directions the country appears to be now going, with certainly varied results. The AWS SENSE Program is a real achievable, sustainable and proven solution for consistent and globally recognized welder training and certification [8]. There are hundreds of high 
schools and colleges in the USA and other countries who have adopted the AWS SENSE Program and benefit greatly from this approach.

\section{REFERENCES}

[1] The Coming Workforce Crisis in Welding https://www.linkedin.com/pulse/comingworkforce-crisis-welding-neil-le-quesne May 2017

[2] Labor Market Research and Analysis Branch Department of Employment Australian Government Office of Employment Structural Steel and Welding Trades Workers, and Fitters Australian Capital Territory "Current labor market ratings" October 2016

[3] USAID 2015. Analysis of Skills Demand in Indonesia, Leader with Associate (LWA) Cooperative Agreement No. EEM-A-00-06-00001-00 USAID publication prepared by John Lindsay, Lara Goldmark, Alec Hansen, Caroline Fawcett, and Eleanor Wang through FHI 360's Workforce Connections project. This work was in response to a request from USAID/Indonesia to support the Mission to better understand the drivers of skills needs in Indonesia

[4] www.unescobkk.org/fileadmin/user_upload/epr/TVET/INDONESIA_PPT.pdf March 2015. UNESCO-Indonesia Qualification Framework, Skills Development and Evaluation System in Indonesia.

[5] Journal of Vocational Education \& Training, ISSN: 1363-6820 (Print) 1747-5090 (Online) Journal homepage: http://www.tandfonline.com/loi/rjve20 Training and skills development in the east Asian, newly industrialized countries: a comparison and lessons for developing countries, ZAFIRIS TZANNATOS, The World Bank, Washington, USA, GERAINT JOHNES, Lancaster University, United Kingdom

[6] Linking Vocational Training with the Enterprises -Asian Perspectives, Authors: Chana Kasipar, Mac Van Tien, Se-Yung LIM, Pham Le Phuong, Phung Quang Huy, Alexander Schnarr, Wu Quanquan, Xu Ying, Frank Bünning Published by: InWEnt - Capacity Building International, in cooperation with the UNESCO-UNEVOC International, Centre for Technical and Vocational Education and Training, Year of publication: 2009, Number of pages: 96, ISBN: 978-3-939394-39-6

[7] Publication: Today, p 13, Date: 5 November 2016-Headline: Indonesian graduates short on industry skills: Study

[8] Creating a Seamless Transition from School to Work Written by Samuel Colton https://nccercornerstone.org/industry/instructor-insight/item/119-creating-a-seamlesstransition-from-school-to-work, May 7, 2013

[9] Anton Hermansyah, The Jakarta Post Jakarta | Wed, November 30, 2016 